Article

\title{
Alterations in the Proteome and Phosphoproteome Profiles of Rat Hippocampus after Six Months of Morphine Withdrawal: Comparison with the Forebrain Cortex
}

\author{
Hana Ujcikova ${ }^{1, *(\mathbb{D})}$, Adam Eckhardt ${ }^{2}$, Lucie Hejnova ${ }^{3}$, Jiri Novotny ${ }^{3}(\mathbb{D})$ and Petr Svoboda ${ }^{1}$ \\ 1 Laboratory of Membrane Receptors, Department of Neurochemistry, Institute of Physiology of the Czech \\ Academy of Sciences, Videnska 1083, 14220 Prague 4, Czech Republic; svobodap@fgu.cas.cz \\ 2 Laboratory of Translational Metabolism, Institute of Physiology of the Czech Academy of Sciences, \\ Videnska 1083, 14220 Prague 4, Czech Republic; adam.eckhardt@fgu.cas.cz \\ 3 Department of Physiology, Faculty of Science, Charles University, Vinicna 7, 12843 Prague 2, Czech Republic; \\ lucie.hejnova@natur.cuni.cz (L.H.); jiri.novotny@natur.cuni.cz (J.N.) \\ * Correspondence: hana.ujcikova@fgu.cas.cz
}

Citation: Ujcikova, H.; Eckhardt, A.; Hejnova, L.; Novotny, J.; Svoboda, P. Alterations in the Proteome and Phosphoproteome Profiles of Rat Hippocampus after Six Months of Morphine Withdrawal: Comparison with the Forebrain Cortex.

Biomedicines 2022, 10, 80 .

https://doi.org/10.3390/

biomedicines 10010080

Academic Editor:

Estela Castilla Ortega

Received: 25 November 2021

Accepted: 28 December 2021

Published: 31 December 2021

Publisher's Note: MDPI stays neutral with regard to jurisdictional claims in published maps and institutional affiliations.

Copyright: (C) 2021 by the authors. Licensee MDPI, Basel, Switzerland. This article is an open access article distributed under the terms and conditions of the Creative Commons Attribution (CC BY) license (https:// creativecommons.org/licenses/by/ $4.0 /$ )

\begin{abstract}
The knowledge about proteome changes proceeding during protracted opioid withdrawal is lacking. Therefore, the aim of this work was to analyze the spectrum of altered proteins in the rat hippocampus in comparison with the forebrain cortex after 6-month morphine withdrawal. We utilized 2D electrophoretic workflow (Pro- $\mathrm{Q}^{\circledR}$ Diamond staining and Colloidal Coomassie Blue staining) which was preceded by label-free quantification (MaxLFQ). The phosphoproteomic analysis revealed six significantly altered hippocampal (Calm1, Ywhaz, Tuba1b, Stip1, Pgk1, and Aldoa) and three cortical proteins (Tubb2a, Tuba1a, and Actb). The impact of 6-month morphine withdrawal on the changes in the proteomic profiles was higher in the hippocampus-14 proteins, only three proteins were detected in the forebrain cortex. Gene Ontology (GO) enrichment analysis of differentially expressed hippocampal proteins revealed the most enriched terms related to metabolic changes, cytoskeleton organization and response to oxidative stress. There is increasing evidence that energy metabolism plays an important role in opioid addiction. However, the way how morphine treatment and withdrawal alter energy metabolism is not fully understood. Our results indicate that the rat hippocampus is more susceptible to changes in proteome and phosphoproteome profiles induced by 6-month morphine withdrawal than is the forebrain cortex.
\end{abstract}

Keywords: protracted morphine withdrawal; rat hippocampus; rat brain cortex; gel-based proteomics; energy metabolism; oxidative stress; nLC-MS/MS

\section{Introduction}

Morphine is still considered a frequently used opioid in the treatment of moderate to severe pain. However, repetitive clinical use has many negative side effects [1,2]. The analgesic effect is caused by the activation of the opioid receptors (ORs). It has a high affinity for $\mu-\mathrm{OR}(\mathrm{MOR})$ and a lower affinity for $\kappa-\mathrm{OR}(\mathrm{KOR})$ and $\delta$-OR (DOR) $[3,4]$.

During the last years, we published several animal studies related to the consequences of morphine treatment and withdrawal. Bourova et al. [5] described that exposure of rats to increasing doses of morphine (10-50 mg/ kg, 10 days) results in significant desensitization of $\mu$-OR- and $\delta$-OR-stimulated $G$ protein response in the rat forebrain cortex. These findings were in agreement with the data published previously [6-11]. Ujcikova et al. [12] detected specific increased level of adenylyl cyclase I (8-fold) and adenylyl cyclase II (2.5-fold) in rat brain cortical plasma membrane samples after 10-day morphine treatment which returned to control level after 20 days of morphine withdrawal. There was no change in the expression level of other adenylyl cyclase isoforms (III-IX). Quantitative immunoblot analysis indicated the unchanged level of $G$ protein $\alpha$ and $\beta$ subunits: $G \alpha_{i 1} / G \alpha_{i 2}, G \alpha_{i 3}, G \alpha_{0}$, $\mathrm{G} \alpha_{\mathrm{q}} / \mathrm{G} \alpha_{11}, \mathrm{G} \alpha_{\mathrm{s}}, \mathrm{G} \alpha_{\mathrm{z}}$, and $\mathrm{G} \beta$. The same applied to Na, K-ATPase, and caveolin-1 [12,13]. 
We applied 2D electrophoretic proteomic approach accompanied by label-free quantification to analyze the altered proteins in the rat brain after 10-day morphine administration followed by protracted drug abstinence [14-17]. The identified proteins were mainly involved in the change of energy metabolism, regulation of the cytoskeleton, signal transduction, oxidative stress pathways, and apoptotic pathways. Similar to our results, a number of studies indicated that chronic morphine treatment causes significant changes in the expression level of metabolic enzymes, cytoskeletal proteins, and apoptosis-related proteins [18-27]. These data may support the idea that long-term morphine treatment dysregulates brain energy homeostasis, increases the degree of neuroplasticity, and causes the state of brain cell discomfort [14,15].

Interestingly, we obtained the opposite results in the rat brain cortex and hippocampus. The number of altered proteins was decreased in the cortical samples and increased in the hippocampus after 20 days of morphine withdrawal [16]. Proteomic and phosphoproteomic comparison of the four rat brain parts (cortex, hippocampus, striatum, and cerebellum) isolated from animals after 3 months of drug abstinence demonstrated that withdrawal symptoms may last for weeks or even longer [17]. In the present study, we extended the withdrawal period from 3 to 6 months and applied gel-based proteomics to analyze the alterations in both protein expression and protein phosphorylation in the rat hippocampus and forebrain cortex. This could be a valuable addition to our previous study in which label-free quantification (MaxLFQ) was used to identify changes in the proteomic profiles of these brain parts [28]. Although shotgun proteomics may generate a large list of proteins, it does not bring information about protein isoforms and post-translational modifications. For this purpose, 2D gel electrophoresis is the only currently available proteomic technique [29].

\section{Materials and Methods}

\subsection{Chemicals}

Chemicals for 2D electrophoresis (Immobiline DryStrips, pH 3-11 NL, $13 \mathrm{~cm}$ ) were obtained from Cytiva (Marlborough, MA, USA), Invitrogen ${ }^{\mathrm{TM}}$ (Pro- $\mathrm{Q}^{\circledR}$ Diamond Phosphoprotein Gel Stain and Gel Destaining Solution) and Sigma-Aldrich (St. Louis, MO, USA) as described by Ujcikova et al. [17].

\subsection{Morphine Administration and Drug Withdrawal of Male Wistar Rats}

Rats ( 8 weeks of age) were exposed to increasing doses of morphine (dissolved in $0.9 \% \mathrm{NaCl})$ for 10 days $(10-50 \mathrm{mg} / \mathrm{kg}$ ) in parallel with corresponding control animals according to our previously established protocols [5,12,14-17,28] approved by the Ministry of Education, Youth and Sports of the Czech Republic (license number MSMT-1479/2019-6). Male Wistar rats were housed in the group of 3 per plastic cage on a 12/12 light/dark cycle. Food and water were available ad libitum. Described procedures were performed in an agreement with national and institutional guidelines for the care and use of animals in laboratory research.

\subsection{Preparation of Samples}

According to our experience and considering the sufficient amount of biological material needed for analyses, we used 9 animals of each testing group for the isolation of the brain cortex, hippocampus, striatum and cerebellum. The tissue from 3 randomly selected animals within the same group was pooled into one sample to obtain three equal amounts of brain tissues.

Finally, we obtained six pooled hippocampal (M1, M2, M3, C1, C2, C3), six pooled cortical (M1, M2, M3, C1, C2, C3), six pooled striatal (M1, M2, M3, C1, C2, C3), and six pooled cerebellar (M1, M2, M3, C1, C2, C3) samples which were homogenized as described by Ujcikova et al. [17] and Drastichova et al. [28]. Protein concentration was determined by Lowry method. 


\subsection{Detection of Phosphoproteins by Pro- $Q^{\circledR}$ Diamond Staining}

Isoelectric focusing of samples containing $1 \mathrm{mg}$ protein was performed according to our previously established scheme: $150 \mathrm{~V}$ for $5 \mathrm{~h}, 500 \mathrm{~V}$ for $1 \mathrm{~h}, 3500 \mathrm{~V}$ for $12 \mathrm{~h}$, and $500 \mathrm{~V}$ for $3 \mathrm{~h}$ [15-17]. SDS-PAGE was followed by gel fixation in $250 \mathrm{~mL}$ of $50 \%$ methanol/10\% acetic acid for $30 \mathrm{~min}$ and overnight with gentle agitation [30]. After three times washing in ultrapure water for $10 \mathrm{~min}$, the gels were incubated in $160 \mathrm{~mL}$ of Pro-Q ${ }^{\circledR}$ Diamond stain solution for $120 \mathrm{~min}$ in the dark. Pro- $\mathrm{Q}^{\circledR}$ Diamond gel destaining solution was used three times for $30 \mathrm{~min}$ in the dark [17].

\subsection{Scanning of Phosphorylated Proteins}

2D gels were scanned by using Amersham Typhoon Biomolecular Imager (GE Healthcare). Laser excitation wavelength: $532 \mathrm{~nm}$ (green), emission filter wavelength: Cy3, 560-580 nm. Scan speed: normal, pixel size: $100 \mu \mathrm{m}$, voltage of the photo-multipliertube (PMT): $750 \mathrm{~V}$.

\subsection{Staining by Colloidal Coomassie Blue (CBB)}

CBB staining was used for detection of protein spots on 2D gels and subsequent mass spectrometric analysis as described in [14-16].

\subsection{Statistical Analysis}

The PDQuest ${ }^{\mathrm{TM}}$ software (Bio-Rad, version 7.3.1, Hercules, CA, USA) was used for evaluation of 2D gels. Protein spots were then checked manually. Relative abundances of protein spots showing significant quantitative differences at least 1.4 -fold $(p \leq 0.05)$ were selected for mass spectrometric analysis. $p$-values were calculated by using unpaired Student's t-test and GraphPadPrism 8.3.0. Gene Ontology (GO) enrichment analysis of proteomic and phosphoproteomic profiles for rat brain hippocampus and cortex was performed using ShinyGO v0.74 tool in 20 October 2021 (bioinformatics.sdstate.edu/go, accessed on 20 October 2021); the $p$-value cut-off (FDR) was set to 0.05 for biological processes.

\section{8. $n L C-M S / M S$}

Protein spots were excised from the polyacrylamide gels and then analyzed as described in [17,31,32]. Briefly, after purification with STAGE-TIPs, peptide separation was achieved using a nano-LC device (Proxeon, Odense, Denmark) coupled to a maXis Q-TOF (quadrupole-time of flight) mass spectrometer with ultra-high resolution (Bruker Daltonics, Bremen, Germany). Appropriate software was used (HyStar 3.2 and MicroTOF control Version 3.0., ProteinScape 3.0 and DataAnalysis 4.0 (Bruker Daltonics, Billerica, MA, USA)) for data analysis. Only significant hits (MASCOT score $\geq 80$ for proteins; $\geq 30$ for peptides) were accepted. Proteins were identified by correlating tandem mass spectra with the UniProt/Swiss-Prot database (taxonomy = Rattus norvegicus). The MASCOT online search engine (http:/ / www.matrixscience.com) was used. All nLC-MS/MS analyses were performed in duplicates (two samples per spot).

\section{Results}

3.1. Proteomic Analysis of the Rat Hippocampus Isolated from Animals after 6 Months of Morphine Withdrawal

\subsubsection{Pro- $\mathrm{Q}^{\circledR}$ Diamond Staining and Colloidal Coomassie Blue Staining of 2D Gels}

Pro-Q ${ }^{\circledR}$ Diamond staining and PDQuest analysis detected 82 protein spots in the rat hippocampus. Among these, six were significantly altered ( $p \leq 0.05)$. nLC-MS/MS analysis identified three upregulated proteins (calmodulin-1 $\uparrow 2.3$-fold, spot 1 ; 14 -3-3 protein zeta / delta $\uparrow 2$.4-fold, spot 2; tubulin alpha-1B chain $\uparrow 3.2$-fold, spot 3 ) and three downregulated proteins (stress-induced-phosphoprotein $1 \downarrow 3.5$-fold, spot 4; phosphoglycerate kinase $1 \downarrow 2$.2-fold, spot 5; fructose-bisphosphate aldolase A $\downarrow 2$.7-fold, spot 6), Figure 1a, Table 1a.

Colloidal Coomassie Blue staining (CBB) revealed 111 protein spots, 16 spots were found to differ significantly. Eleven altered proteins were downregulated (peroxiredoxin-2 
$\downarrow$ 3.1-fold, spot 1; phosphatidylethanolamine-binding protein $1 \downarrow 2$.6-fold, spot 2; ubiquitin carboxyl-terminal hydrolase isozyme L1 $\downarrow 2$.0-fold, spot 3; beta-soluble NSF attachment protein $\downarrow 2$.4-fold, spot 4; guanine nucleotide-binding protein $G(\mathrm{I}) / \mathrm{G}(\mathrm{S}) / \mathrm{G}(\mathrm{T})$ subunit beta-1 $\downarrow 2$.4-fold, spot 5; endophilin-A1 $\downarrow 7$.8-fold, spot 6 ; actin, cytoplasmic $1 \downarrow 1$.6-fold, spot 7; creatine kinase B-type $\downarrow$ 1.6-fold and $\downarrow 2$.3-fold, spot 8 and spot 9; tubulin beta chain $\downarrow 1$.9-fold and $\downarrow$ 6.1-fold, spot 10 and spot 13; alpha internexin $\downarrow 2$.4-fold, spot 11; stress-70 protein, mitochondrial $\downarrow 3.1$-fold, spot 12), and three proteins were upregulated (ATP synthase subunit d, mitochondrial $\uparrow 6.7$-fold, spot 14; Parkinson disease protein 7 homolog $\uparrow 2.0$-fold, spot 15; triosephosphate isomerase $\uparrow 1.9$-fold, spot 16), Figure 1b, Table 1b.

According to the current annotations (https: / / www.uniprot.org, accessed on 20 October 2021) in the UniProt database, the identified hippocampal proteins were involved in metabolism (5), cytoskeleton organization (4), signal transduction (3), protein folding (3), response to oxidative stress (3), brain development (3), transport (3), aging (2), apoptosis (1), and protein ubiquitination (1) (Figure 2b; Table 2a,b).
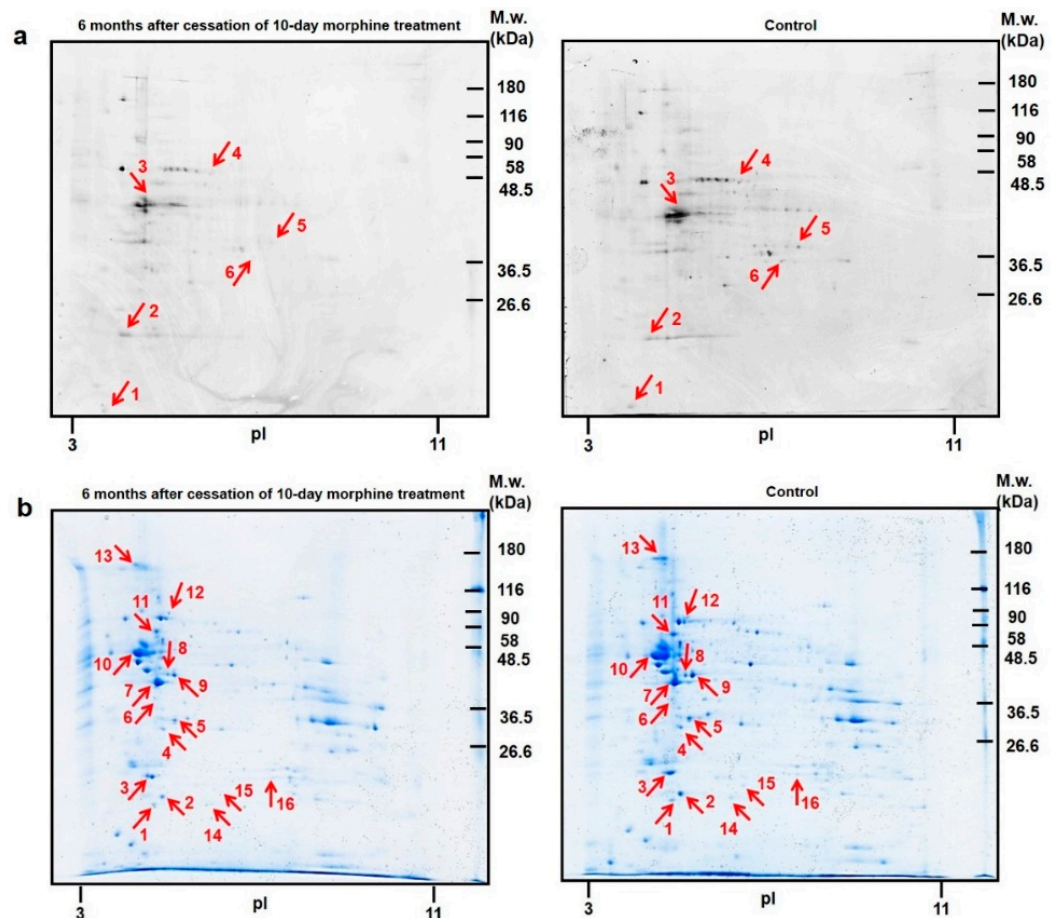

Figure 1. Representative 2D gel maps of phosphorylated proteins (a) and total protein profiles (b) in the rat hippocampus isolated from animals after 6 months of morphine withdrawal. Red arrows and numbers show the significantly altered protein spots.

\subsubsection{GO Enrichment Analysis of Altered Hippocampal Proteins}

GO enrichment analysis of 20 significantly differentially expressed hippocampal proteins was carried out using the ShinyGO v0.74 tool (bioinformatics.sdstate.edu/go). The top thirty most significantly enriched GO terms for biological processes were summarized in hierarchical clustering tree, see Figure 3. The most enriched GO terms were related to metabolic changes: phosphorus metabolic process, phosphate-containing compound metabolic process, ATP metabolic process, methylglyoxal metabolic process, generation of precursor metabolites and energy, nucleoside phosphate metabolic process, nucleotide metabolic process; cytoskeleton organization: postsynaptic cytoskeleton organization, establishment of localization in cell, postsynaptic actin cytoskeleton organization, and oxidative stress: removal of superoxide radicals, response to superoxide, response to oxygen radical. The detailed data of these GO enriched terms are listed in Table 3, including enrichment FDR values and gene names of altered proteins associated with GO terms. 


\section{Hippocampus}

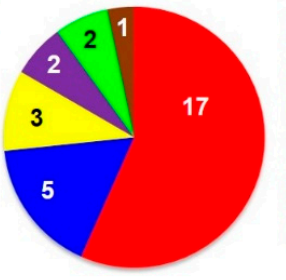

$\square$ cytoplasm

cell membrane

nucleus

mitochondrion

endoplasmic reticulum

melanosome b

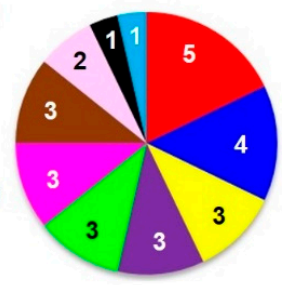

metabolism

cytoskeleton organization

signal transduction

protein folding

oxidative stress

brain development

transport

aging

apoptosis

Cortex

protein ubiquitination

C

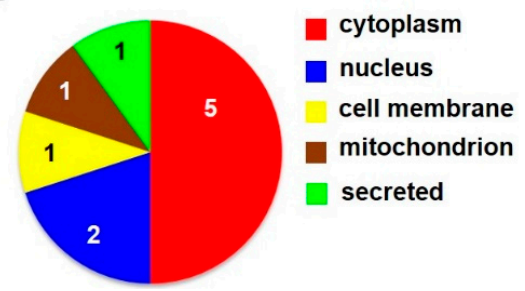

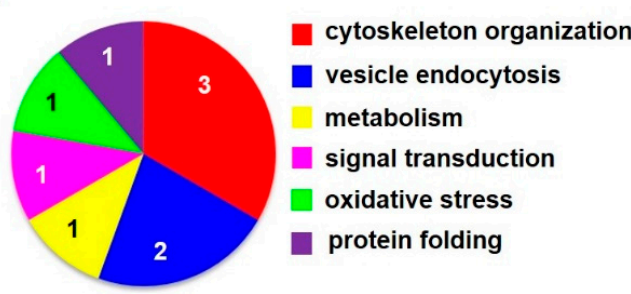

Figure 2. Subcellular localization $(\mathbf{a}, \mathbf{c})$ and function $(\mathbf{b}, \mathbf{d})$ of altered proteins identified in the rat hippocampus (upper panels) and cortex (lower panels) isolated from animals after 6 months of morphine withdrawal; according to the current annotations (https://www.uniprot.org) in the UniProt database.

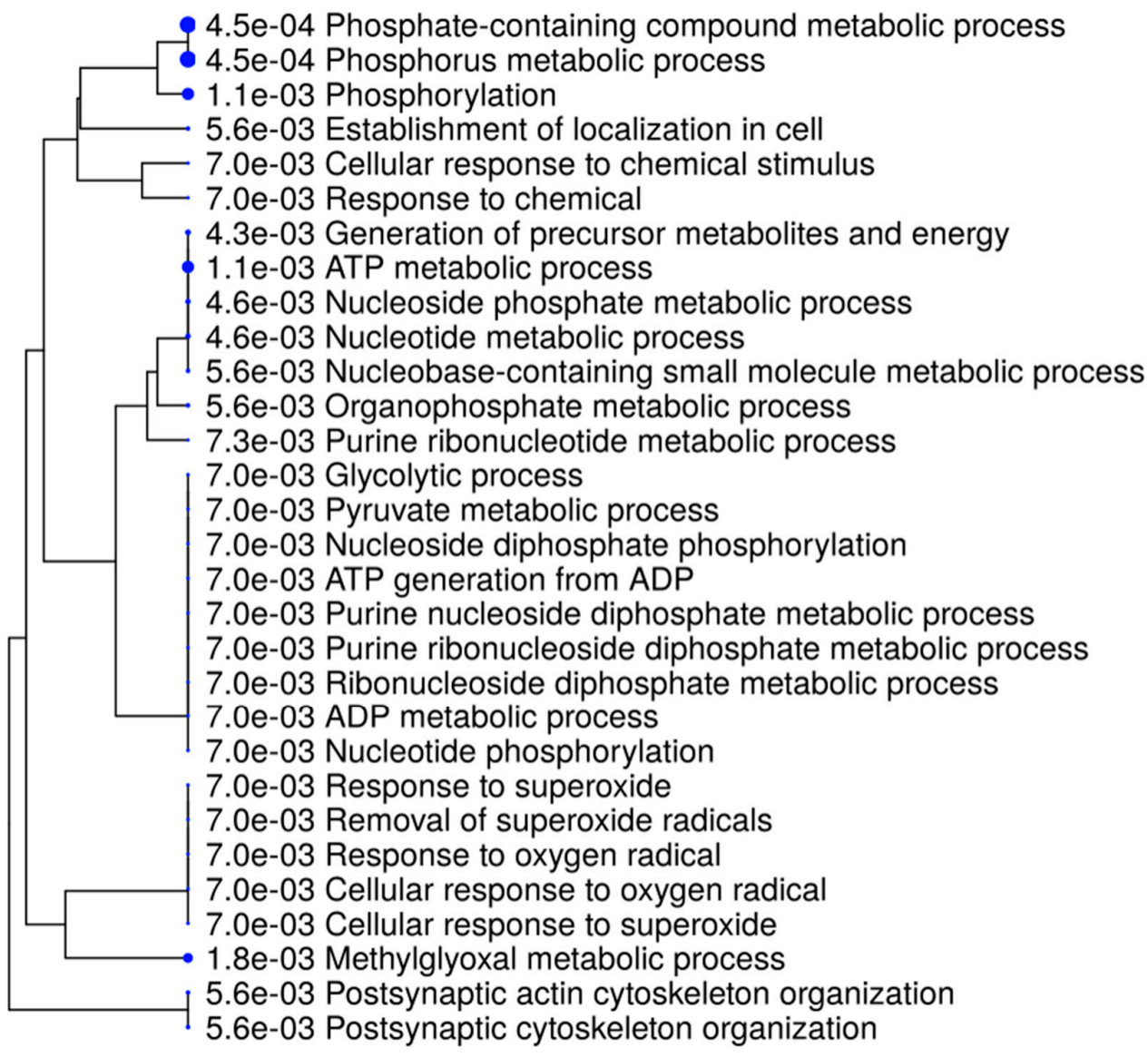

Figure 3. Hierarchical clustering tree summarizing the top 30 most significantly enriched GO terms that were identified in rat hippocampus. The analyzed dataset was consisted of 20 significantly differentially expressed hippocampal proteins. 
Table 1. nLC-MS/MS analysis of significantly altered protein spots identified in the rat hippocampus (a,b) and cortex (c,d) isolated from animals after 6 months of morphine withdrawal.

\begin{tabular}{|c|c|c|c|c|c|c|c|c|c|c|}
\hline Spot & Accession & Gene & Protein Name & Mascot & Matched & $\mathrm{SC}^{\mathrm{a}}$ & $\mathbf{M W}^{\mathrm{b}}$ & $\mathrm{pI}^{\mathrm{c}}$ & Change & $p$ Value \\
\hline & Number & & & Score & Peptides & {$[\%]$} & (kDa) & & (Fold) & \\
\hline \multicolumn{11}{|c|}{ (a) HIPPOCAMPUS Pro- $Q^{\circledR}$ Diamond staining } \\
\hline 1 & P0DP29 & Calm1 & Calmodulin-1 & 2299.5 & 28 & 93.3 & 16.8 & 3.9 & $\uparrow 2.3$ & 0.0316 \\
\hline 2 & P63102 & Ywhaz & 14-3-3 protein zeta/delta & 1654.2 & 25 & 74.7 & 27.8 & 4.6 & $\uparrow 2.4$ & 0.0014 \\
\hline 3 & Q6P9V9 & Tuba1b & Tubulin alpha-1B chain & 1866.7 & 27 & 57.9 & 50.1 & 4.8 & $\uparrow 3.2$ & 0.0424 \\
\hline 4 & O35814 & Stip1 & Stress-induced phosphoprotein 1 & 1728.2 & 32 & 39.4 & 62.5 & 6.4 & $\downarrow 3.5$ & 0.0309 \\
\hline 5 & P16617 & Pgk1 & Phosphoglycerate kinase 1 & 2026.8 & 36 & 57.8 & 44.5 & 9.0 & $\downarrow 2.2$ & 0.0195 \\
\hline 6 & P05065 & Aldoa & Fructose-bisphosphate aldolase A & 2243.8 & 35 & 80.2 & 39.3 & 9.2 & $\downarrow 2.7$ & 0.0084 \\
\hline \multicolumn{11}{|c|}{ (b) HIPPOCAMPUS Colloidal Coommassie Blue staining } \\
\hline 1 & P35704 & $\operatorname{Prdx} 2$ & Peroxiredoxin-2 & 429.6 & 8 & 33.8 & 21.8 & 5.2 & $\downarrow 3.1$ & 0.0036 \\
\hline 2 & P31044 & Pebp1 & $\begin{array}{l}\text { Phosphatidylethanolamine-binding } \\
\text { protein } 1\end{array}$ & 988.5 & 13 & 62.6 & 20.8 & 5.4 & $\downarrow 2.6$ & 0.0004 \\
\hline 3 & Q00981 & Uchl1 & $\begin{array}{l}\text { Ubiquitin carboxyl-terminal hydrolase } \\
\text { isozyme L1 }\end{array}$ & 1462.4 & 24 & 59.6 & 24.8 & 5.0 & $\downarrow 2.0$ & 0.0394 \\
\hline 4 & F8WFM2 & $\mathrm{Napb}$ & Beta-soluble NSF attachment protein & 1276.3 & 20 & 55.4 & 33.5 & 5.2 & $\downarrow 2.4$ & 0.0015 \\
\hline 5 & P54311 & Gnb1 & $\begin{array}{l}\text { Guanine nucleotide-binding protein } \\
G(\mathrm{I}) / \mathrm{G}(\mathrm{S}) / \mathrm{G}(\mathrm{T}) \text { subunit beta-1 }\end{array}$ & 728.3 & 12 & 33.2 & 37.4 & 5.6 & $\downarrow 2.4$ & 0.0045 \\
\hline 6 & O35179 & Sh3gl2 & Endophilin-A1 & 1368.9 & 28 & 34.4 & 39.9 & 5.1 & $\downarrow 7.8$ & 0.0363 \\
\hline 7 & P60711 & Actb & Actin, cytoplasmic 1 & 2492.6 & 38 & 62.7 & 41.7 & 5.2 & $\downarrow 1.8$ & 0.0293 \\
\hline 8 & P07335 & $\mathrm{Ckb}$ & Creatine kinase B-type & 2008.6 & 27 & 57 & 42.7 & 5.3 & $\downarrow 1.6$ & 0.0402 \\
\hline 9 & P07335 & $\mathrm{Ckb}$ & Creatine kinase B-type & 2337.6 & 34 & 65.4 & 42.7 & 5.3 & $\downarrow 2.3$ & 0.0026 \\
\hline 10 & G3V7C6 & Tubb4b & Tubulin beta chain & 2983.9 & 37 & 49.8 & 61.1 & 4.6 & $\downarrow 1.9$ & 0.0358 \\
\hline 11 & P23565 & Ina & Alpha-internexin & 2688.1 & 41 & 75.6 & 56.1 & 5.1 & $\downarrow 2.4$ & 0.0117 \\
\hline 12 & F1M953 & Hspa9 & Stress-70 protein, mitochondrial & 2772.9 & 43 & 41.7 & 73.7 & 5.8 & $\downarrow 3.1$ & 0.0127 \\
\hline 13 & G3V7C6 & Tubb4b & Tubulin beta chain & 1809.5 & 23 & 40.5 & 61.1 & 4.6 & $\downarrow 6.1$ & 0.0175 \\
\hline
\end{tabular}


Table 1. Cont.

\begin{tabular}{|c|c|c|c|c|c|c|c|c|c|c|}
\hline Spot & Accession & Gene & Protein Name & Mascot & Matched & $\mathrm{SC}^{\mathrm{a}}$ & $\mathbf{M W}^{\mathbf{b}}$ & $\mathrm{pI}^{\mathrm{c}}$ & Change & $p$ Value \\
\hline & Number & & & Score & Peptides & {$[\%]$} & $(\mathrm{kDa})$ & & (Fold) & \\
\hline 14 & P31399 & Atp5pd & ATP synthase subunit $d$, mitochondrial & 1680.6 & 23 & 67.7 & 18.8 & 6.2 & $\uparrow 6.7$ & 0.0011 \\
\hline 16 & P48500 & Tpi1 & Triosephosphate isomerase & 829.1 & 12 & 53 & 26.8 & 7.7 & $\uparrow 1.9$ & 0.0348 \\
\hline \multicolumn{11}{|c|}{ (c) CORTEX Pro- $Q^{\circledR}$ Diamond staining } \\
\hline 1 & P85108 & Tubb2a & Tubulin beta-2A chain & 3071.4 & 37 & 73 & 49.9 & 4.6 & $\downarrow 2.4$ & 0.0103 \\
\hline 2 & P68370 & Tuba1a & Tubulin alpha-1A chain & 1538.3 & 21 & 47 & 50.1 & 4.8 & $\downarrow 3.7$ & 0.0406 \\
\hline 3 & P60711 & Actb & Actin, cytoplasmic 1 & 1532.3 & 23 & 50.9 & 41.7 & 5.2 & $\downarrow 2.7$ & 0.0284 \\
\hline \multicolumn{11}{|c|}{ (d) CORTEX Colloidal Coommassie Blue staining } \\
\hline 1 & P0DP29 & Calm1 & Calmodulin-1 & 1670.9 & 18 & 74.5 & 16.8 & 3.9 & $\downarrow 2.0$ & 0.0478 \\
\hline 2 & P37377 & Snca & Alpha-synuclein & 1287.2 & 16 & 80 & 14.5 & 4.6 & $\downarrow 1.4$ & 0.0114 \\
\hline 3 & Q99NA5 & Idh3a & $\begin{array}{l}\text { Isocitrate dehydrogenase [NAD] subunit } \\
\text { alpha, mitochondrial }\end{array}$ & 830.1 & 9 & 28 & 39.6 & 6.5 & $\uparrow 2.4$ & 0.0252 \\
\hline
\end{tabular}

${ }^{\mathrm{a}}$ sequence coverage, ${ }^{\mathrm{b}}$ theoretical molecular weight, ${ }^{\mathrm{c}}$ theoretical isoelectric point.

Table 2. Subcellular localization and function of altered proteins identified in the rat hippocampus (a,b) and cortex (c,d) isolated from animals after 6 months of morphine withdrawal; according to the current annotations (https: / www.uniprot.org) in the UniProt database.

\begin{tabular}{|c|c|c|c|c|c|}
\hline Spot & Accession & Protein Name & Change & Subcellular Localization & GO-Molecular Functions, Biological Processes \\
\hline & Number & & (Fold) & & \\
\hline \multicolumn{6}{|c|}{ (a) HIPPOCAMPUS Pro-Q $Q^{\circledR}$ Diamond staining } \\
\hline 1 & P0DP29 & Calmodulin-1 & $\uparrow 2.3$ & Cytoplasm, cytoskeleton & $\begin{array}{l}\text { Calcium-mediated signaling, activation } \\
\text { of adenylate cyclase activity, regulation of cytokinesis }\end{array}$ \\
\hline 2 & P63102 & 14-3-3 protein zeta/delta & $\uparrow 2.4$ & Cytoplasm, melanosome & Signal transducing adaptor protein \\
\hline 3 & Q6P9V9 & Tubulin alpha-1B chain & $\uparrow 3.2$ & Cytoplasm, cytoskeleton & Cell shape and movement \\
\hline 5 & P16617 & Phosphoglycerate kinase 1 & $\downarrow 2.2$ & Cytoplasm & Energy metabolism (glycolysis) \\
\hline 6 & P05065 & Fructose-bisphosphate aldolase A & $\downarrow 2.7$ & Cytoplasm & Energy metabolism (glycolysis) \\
\hline
\end{tabular}


Table 2. Cont.

\begin{tabular}{|c|c|c|c|c|c|}
\hline Spot & Accession & Protein Name & Change & Subcellular Localization & GO-Molecular Functions, Biological Processes \\
\hline & Number & & (Fold) & & \\
\hline \multicolumn{6}{|c|}{ (b) HIPPOCAMPUS Colloidal Coommassie Blue staining } \\
\hline 1 & P35704 & Peroxiredoxin-2 & $\downarrow 3.1$ & Cytoplasm & Antioxidant, response to oxidative stress \\
\hline 2 & P31044 & $\begin{array}{l}\text { Phosphatidylethanolamine-binding } \\
\text { protein } 1\end{array}$ & $\downarrow 2.6$ & Cytoplasm, cell membrane & $\begin{array}{l}\text { Hippocampus development, aging, response } \\
\text { to oxidative stress, MAPK cascade }\end{array}$ \\
\hline 3 & Q00981 & $\begin{array}{l}\text { Ubiquitin carboxyl-terminal hydrolase } \\
\text { isozyme L1 }\end{array}$ & $\downarrow 2.0$ & Cytoplasm, endoplasmic reticulum & Protein ubiquitination, axonogenesis \\
\hline 4 & F8WFM2 & Beta-soluble NSF attachment protein & $\downarrow 2.4$ & Cell membrane & ER-Golgi transport, protein transport \\
\hline 5 & P54311 & $\begin{array}{l}\text { Guanine nucleotide-binding protein } \\
\mathrm{G}(\mathrm{I}) / \mathrm{G}(\mathrm{S}) / \mathrm{G}(\mathrm{T}) \text { subunit beta-1 }\end{array}$ & $\downarrow 2.4$ & Cell membrane, cytoplasm & Signal transducer \\
\hline 6 & O35179 & Endophilin-A1 & $\downarrow 7.8$ & Cytoplasm, endosome, cell membrane & Endocytosis, regulation of receptor internalization \\
\hline 7 & P60711 & Actin, cytoplasmic 1 & $\downarrow 1.8$ & Cytoplasm, cytoskeleton, nucleus & Cell shape and movement \\
\hline 8,9 & P07335 & Creatine kinase B-type & $\downarrow 1.6, \downarrow 2.3$ & Cytoplasm & Brain development, creatine metabolism \\
\hline 10,13 & G3V7C6 & Tubulin beta chain & $\downarrow 1.9, \downarrow 6.1$ & Cytoplasm, cytoskeleton & Cell shape and movement \\
\hline 12 & F1M953 & Stress-70 protein, mitochondrial & $\downarrow 3.1$ & Mitochondrion & Chaperone \\
\hline 14 & P31399 & ATP synthase subunit $d$, mitochondrial & $\uparrow 6.7$ & Mitochondrion & ATP metabolic process, hydrogen ion transport \\
\hline 15 & O88767 & Parkinson disease protein 7 homolog & $\uparrow 2.0$ & $\begin{array}{l}\text { Cell membrane, cytoplasm, nucleus, } \\
\text { endoplasmic reticulum }\end{array}$ & $\begin{array}{l}\text { Chaperone, aging, inflammatory response, stress } \\
\text { response, negative regulation of apoptosis }\end{array}$ \\
\hline 16 & P48500 & Triosephosphate isomerase & $\uparrow 1.9$ & Cytoplasm & Energy metabolism (glycolysis) \\
\hline \multicolumn{6}{|c|}{ (c) CORTEX Pro- $Q^{\circledR}$ Diamond staining } \\
\hline 1 & P85108 & Tubulin beta-2A chain & $\downarrow 2.4$ & Cytoplasm, cytoskeleton & Cell shape and movement \\
\hline 2 & P68370 & Tubulin alpha-1A chain & $\downarrow 3.7$ & Cytoplasm, cytoskeleton & Cell shape and movement \\
\hline 3 & P60711 & Actin, cytoplasmic 1 & $\downarrow 2.7$ & Cytoplasm, cytoskeleton, nucleus & Cell shape and movement \\
\hline
\end{tabular}


Table 2. Cont.

\begin{tabular}{|c|c|c|c|c|c|}
\hline Spot & Accession & Protein Name & Change & Subcellular Localization & GO-Molecular Functions, Biological Processes \\
\hline & Number & & (Fold) & & \\
\hline \multicolumn{6}{|c|}{ (d) CORTEX Colloidal Coommassie Blue staining } \\
\hline 1 & P0DP29 & Calmodulin-1 & $\downarrow 2.0$ & Cytoplasm, cytoskeleton & $\begin{array}{l}\text { Calcium-mediated signaling, activation of adenylate } \\
\text { cyclase activity, regulation of cytokinesis }\end{array}$ \\
\hline 2 & P37377 & Alpha-synuclein & $\downarrow 1.4$ & Cytoplasm, cell membrane, nucleus, secreted & $\begin{array}{c}\text { Chaperone, response to oxidative stress, regulation of } \\
\text { synaptic vesicle trafficking, regulation of } \\
\text { neurotransmitter release }\end{array}$ \\
\hline 3 & Q99NA5 & $\begin{array}{l}\text { Isocitrate dehydrogenase [NAD] subunit } \\
\text { alpha, mitochondrial }\end{array}$ & $\uparrow 2.4$ & Mitochondrion & Krebs cycle \\
\hline
\end{tabular}

Table 3. GO enrichment analysis for significantly upregulated and downregulated proteins identified in the rat hippocampus isolated from animals after 6 months of morphine withdrawal; carried out using the ShinyGO v0.74 tool (bioinformatics.sdstate.edu/go). The top thirty most significantly enriched GO terms for biological processes are listed.

\begin{tabular}{|c|c|c|c|c|}
\hline Pathways & Enrichment FDR & Pathway & Genes & Name of Genes in List \\
\hline & & Genes & in List & \\
\hline Phosphorus metabolic process & 0.000454130956700965 & 2813 & 12 & Atp5pd, Aldoa, Uchl1, Prdx2, Calm1, Sh3gl2, Ywhaz, Ckb, Tpi1, Park7, Pgk1, Actb \\
\hline Phosphorylation & 0.00109269868079895 & 2072 & 10 & Aldoa, Uchl1, Prdx2, Sh3gl2, Ywhaz, Tpi1, Park7, Pgk1, Actb, Atp5pd \\
\hline ATP metabolic process & 0.00109269868079895 & 272 & 5 & Atp5pd, Aldoa, Tpi1, Park7, Pgk1 \\
\hline Methylglyoxal metabolic process & 0.001813238441941 & 5 & 2 & Park7, Aldoa \\
\hline Generation of precursor metabolites and energy & 0.00432203205106559 & 397 & 5 & Aldoa, Tpi1, Park7, Pgk1, Atp5pd \\
\hline Nucleoside phosphate metabolic process & 0.00464706222526931 & 428 & 5 & Atp5pd, Aldoa, Tpi1, Park7, Pgk1 \\
\hline Nucleotide metabolic process & 0.00464706222526931 & 419 & 5 & Atp5pd, Aldoa, Tpi1, Park7, Pgk1 \\
\hline Postsynaptic cytoskeleton organization & 0.00556835599926725 & 13 & 2 & Ina, Actb \\
\hline Organophosphate metabolic process & 0.00556835599926725 & 820 & 6 & Atp5pd, Aldoa, Ckb, Tpi1, Park7, Pgk1 \\
\hline Establishment of localization in cell & 0.00556835599926725 & 1630 & 8 & Calm1, Ywhaz, Uchl1, Napb, Park7, Hspa9, Actb, Atp5pd \\
\hline Nucleobase-containing small molecule metabolic process & 0.00556835599926725 & 473 & 5 & Atp5pd, Aldoa, Tpi1, Park7, Pgk1 \\
\hline
\end{tabular}


Table 3. Cont.

\begin{tabular}{|c|c|c|c|c|}
\hline Pathways & Enrichment FDR & Pathway & Genes & Name of Genes in List \\
\hline & & Genes & in List & \\
\hline Postsynaptic actin cytoskeleton organization & 0.00556835599926725 & 13 & 2 & Ina, Actb \\
\hline Pyruvate metabolic process & 0.00698656482715899 & 121 & 3 & Aldoa, Tpi1, Pgk1 \\
\hline Glycolytic process & 0.00698656482715899 & 102 & 3 & Aldoa, Tpi1, Pgk1 \\
\hline Nucleoside diphosphate phosphorylation & 0.00698656482715899 & 120 & 3 & Aldoa, Tpi1, Pgk1 \\
\hline ATP generation from ADP & 0.00698656482715899 & 103 & 3 & Aldoa, Tpi1, Pgk1 \\
\hline Purine ribonucleoside diphosphate metabolic process & 0.00698656482715899 & 113 & 3 & Aldoa, Tpi1, Pgk1 \\
\hline Ribonucleoside diphosphate metabolic process & 0.00698656482715899 & 116 & 3 & Aldoa, Tpi1, Pgk1 \\
\hline Removal of superoxide radicals & 0.00698656482715899 & 18 & 2 & Prdx2, Park7 \\
\hline Response to chemical & 0.00698656482715899 & 4423 & 12 & Ywhaz, Gnb1, Uchl1, Prdx2, Calm1, Park7, Ina, Stip1, Actb, Tuba1b, Atp5pd, Aldoa \\
\hline Response to superoxide & 0.00698656482715899 & 21 & 2 & Prdx2, Park7 \\
\hline Response to oxygen radical & 0.00698656482715899 & 21 & 2 & Prdx2, Park7 \\
\hline Nucleotide phosphorylation & 0.00698656482715899 & 122 & 3 & Aldoa, Tpi1, Pgk1 \\
\hline Cellular response to chemical stimulus & 0.00698656482715899 & 2498 & 9 & Gnb1, Uchl1, Prdx2, Park7, Ina, Stip1, Actb, Tuba1b, Atp5pd \\
\hline Cellular response to oxygen radical & 0.00698656482715899 & 19 & 2 & Prdx2, Park7 \\
\hline Cellular response to superoxide & 0.00698656482715899 & 19 & 2 & Prdx2, Park7 \\
\hline Purine ribonucleotide metabolic process & 0.00726512653650191 & 327 & 4 & Atp5pd, Aldoa, Tpi1, Pgk1 \\
\hline
\end{tabular}


3.2. Proteomic Analysis of the Rat Forebrain Cortex Isolated from Animals after 6 Months of Morphine Withdrawal

\subsubsection{Pro- $\mathrm{Q}^{\circledR}$ Diamond Staining and Colloidal Coomassie Blue Staining of 2D Gels}

The 83 phosphorylated protein spots were detected in the rat brain cortex, only three were significantly downregulated: tubulin beta-2A chain $\downarrow 2$.4-fold, spot 1 ; tubulin alpha-1A chain $\downarrow 3$.7-fold, spot 2 and actin, cytoplasmic $1 \downarrow 2$.7-fold, spot 3; Figure 4a, Table 1c.

a

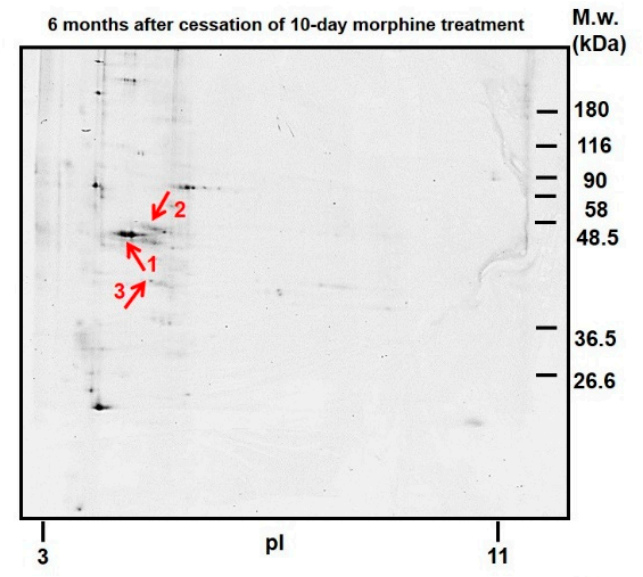

b

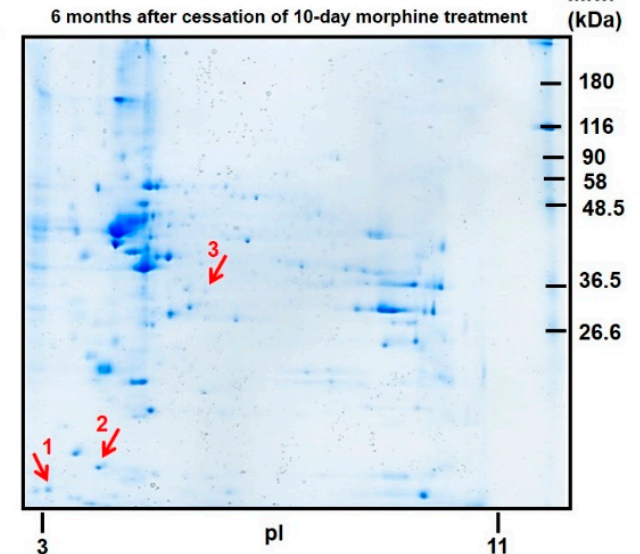

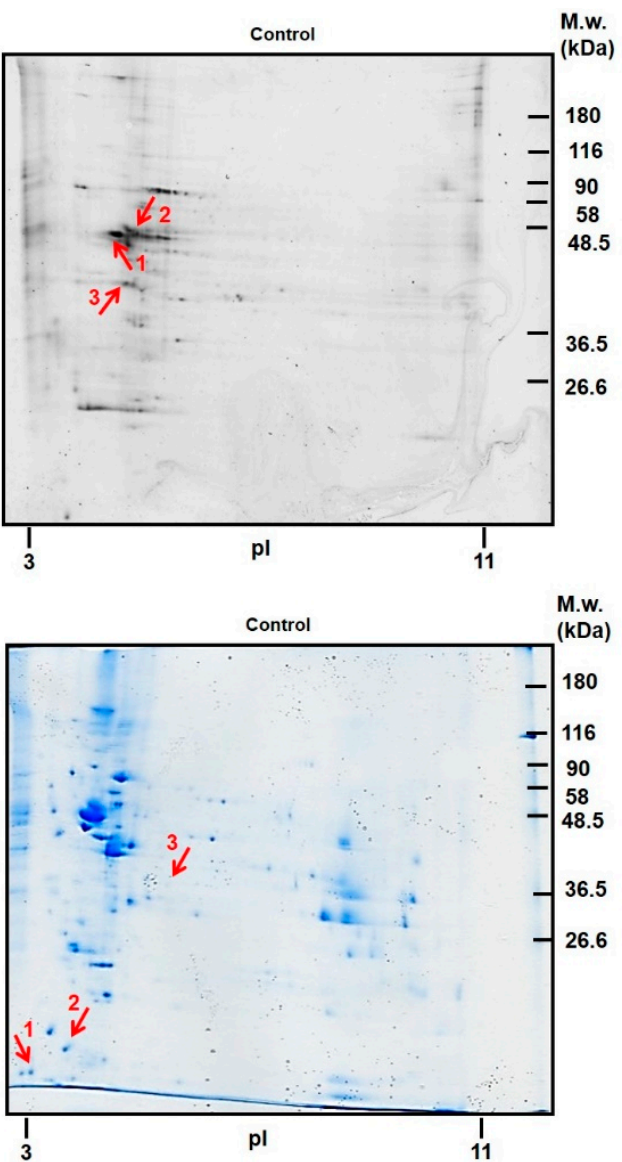

Figure 4. Representative 2D gel maps of phosphorylated proteins (a) and total protein profiles (b) in the rat forebrain cortex isolated from animals after 6 months of morphine withdrawal. Red arrows and numbers show the significantly altered protein spots.

CBB staining revealed 87 protein spots in cortical 2D gels, only three of these were significantly altered. nLC-MS/MS analysis identified two proteins with decreased level (calmodulin $1 \downarrow 2$.0-fold, spot 1; alpha-synuclein $\downarrow$ 1.4-fold, spot 2) and one upregulated protein: mitochondrial isocitrate dehydrogenase [NAD] subunit alpha $\uparrow 2.4$-fold, spot 3; Figure $4 \mathrm{~b}$, Table $1 \mathrm{~d}$.

According to the current annotations (https://www.uniprot.org) in the UniProt database, the identified cortical proteins were functionally related to cytoskeleton organization (3), vesicle endocytosis (2), metabolism (1), signal transduction (1), response to oxidative stress (1), and protein folding (1) (Figure 2d; Table 2c,d).

\subsubsection{GO Enrichment Analysis of Altered Cortical Proteins}

GO enrichment analysis of six significantly differentially expressed cortical proteins (Table 1c,d) was carried out using the ShinyGO v0.74 tool (bioinformatics.sdstate.edu/go). The top ten most significantly enriched GO terms for biological processes were summarized in hierarchical clustering tree (Figure 5). The most enriched GO terms were related to vesicle endocytosis: presynaptic endocytosis, synaptic vesicle endocytosis, synaptic vesicle 
recycling, synaptic vesicle cycle, vesicle-mediated transport in synapse, and regulation of catecholamine uptake. The detailed data of these GO enriched terms are listed in Table 4, including enrichment FDR values and gene names of altered proteins associated with GO terms.

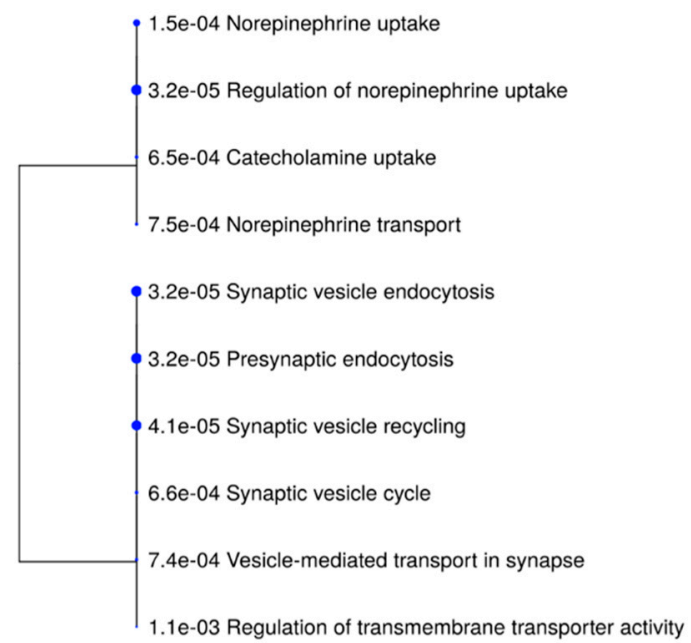

Figure 5. Hierarchical clustering tree summarizing the top 10 most significantly enriched GO terms that were identified in rat forebrain cortex. The analyzed dataset was consisted of 6 significantly differentially expressed cortical proteins.

Table 4. GO enrichment analysis for significantly upregulated and downregulated proteins identified in the rat forebrain cortex isolated from animals after 6 months of morphine withdrawal; carried out using the ShinyGO v0.74 tool (bioinformatics.sdstate.edu/go). The top ten most significantly enriched GO terms for biological processes are listed.

\begin{tabular}{lcccc}
\hline Pathways & Enrichment FDR & Pathway & Genes & Name of Genes in List \\
\hline & & Genes & in List & \\
\hline Presynaptic endocytosis & 0.0000317791916695507 & 41 & 3 & Snca, Actb, Calm1 \\
\hline Synaptic vesicle endocytosis & 0.0000317791916695507 & 41 & 3 & Snca, Actb, Calm1 \\
\hline Regulation of norepinephrine uptake & 0.0000317791916695507 & 2 & 2 & Snca, Actb \\
\hline Synaptic vesicle recycling & 0.0000411603443103439 & 49 & 3 & Snca, Actb, Calm1 \\
\hline Norepinephrine uptake & 0.00014973418795375 & 6 & 2 & Snca, Actb \\
\hline Catecholamine uptake & 0.000648303871273433 & 13 & 2 & Snca, Actb \\
\hline Synaptic vesicle cycle & 0.000655582495341169 & 147 & 3 & Snca, Actb, Calm1 \\
\hline Vesicle-mediated transport in synapse & 0.000739942307588717 & 160 & 3 & Snca, Actb, Calm1 \\
\hline Norepinephrine transport & 0.000753222666338899 & 17 & 2 & Snca, Actb \\
\hline Regulation of transmembrane transporter activity & 0.00113861317223078 & 199 & 3 & Calm1, Snca, Actb \\
\hline
\end{tabular}

3.3. Proteomic Analysis of the Rat Striatum and Cerebellum Isolated from Animals after 6 Months of Morphine Withdrawal

\subsubsection{Colloidal Coomassie Blue Protein Staining of Striatal 2D Gels}

CBB-stained 2D gels revealed 152 protein spots in the rat striatum, ten proteins with significantly changed expression level were identified by nLC-MS/MS analysis. Among these, seven proteins were downregulated: calmodulin-1 $\downarrow 2$.3-fold, spot 1; 1-lactate dehydrogenase B chain $\downarrow 1$.4-fold, spot 3; malate dehydrogenase, cytoplasmic $\downarrow 1$.8-fold, spot 4; albumin $\downarrow 2$.4-fold, spot 7; dihydropyrimidinase-related protein $2 \downarrow 1$.7-fold and $\downarrow 2$.0-fold, spot 8 and spot 9; nucleoside diphosphate kinase B $\downarrow 2$.0-fold, spot 10, and elongation factor 1-alpha $\downarrow 3$.1-fold, spot 11. Only three proteins were upregulated: peroxiredoxin-2 
$\uparrow 1.8$-fold, spot 2 ; actin, cytoplasmic $1 \uparrow 3.3$-fold, spot 5 and heat shock cognate $71 \mathrm{kDa}$ protein $\uparrow 2.5$-fold, spot 6; Figure 6a, Table 5 a.
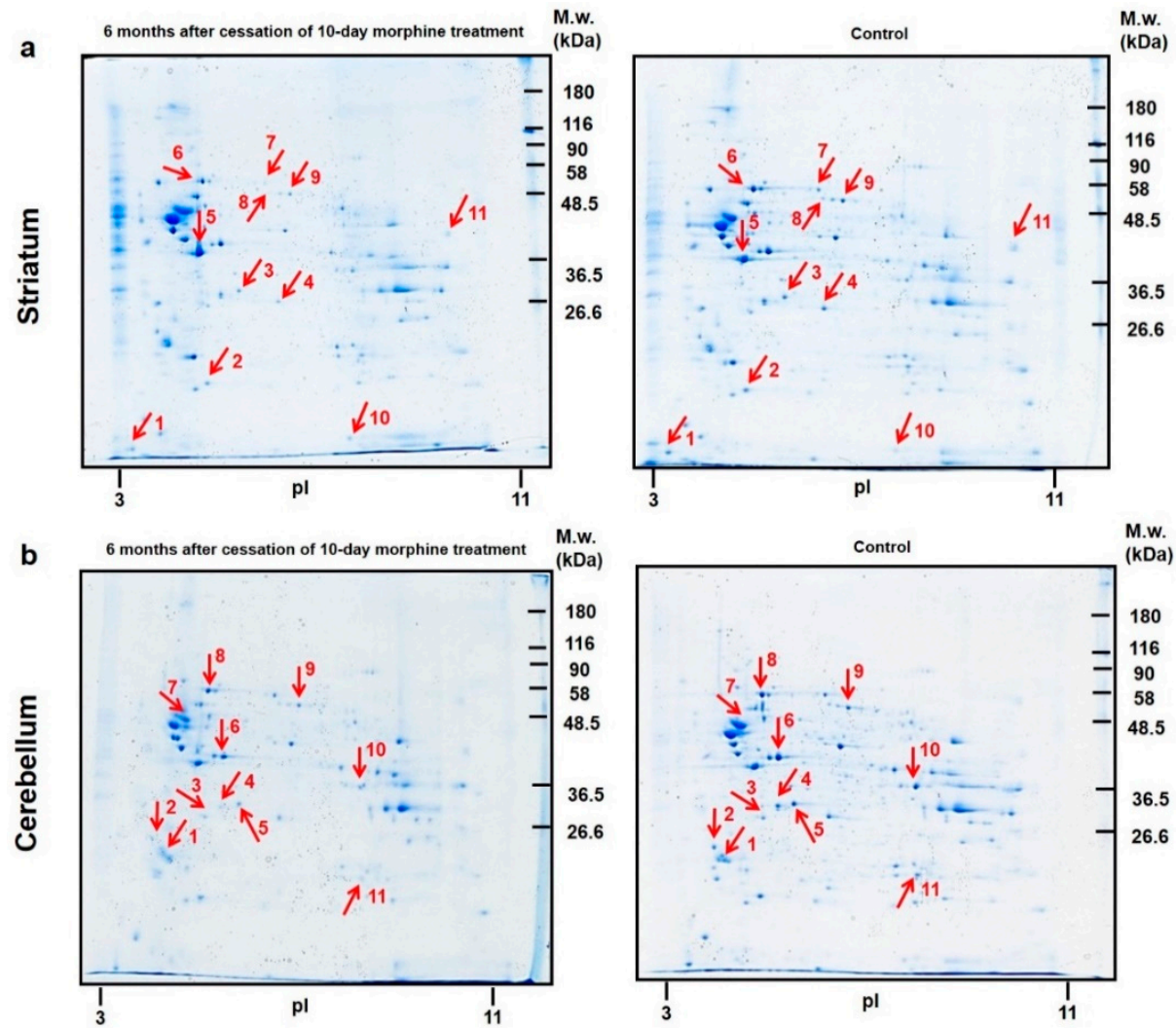

Figure 6. Representative 2D gel maps of total protein profiles in the rat striatum (a, upper panels) and cerebellum (b, lower panels) isolated from animals after 6 months of morphine withdrawal. Red arrows and numbers show the significantly altered protein spots.

According to the current annotations (https: / / www.uniprot.org, accessed on 20 October 2021) in the UniProt database, the altered striatal proteins were found to be functionally related to metabolism (3), RNA processing (3), cytoskeleton organization (2), signal transduction (1), response to oxidative stress (1), protein folding (1), aging (1), brain development (1), and apoptosis (1) (Figure 7b; Table 6a).

\subsubsection{Colloidal Coomassie Blue Protein Staining of Cerebellar 2D Gels}

The total number of 122 protein spots were detected in the rat cerebellum, eleven proteins were significantly downregulated: $14-3-3$ protein gamma $\downarrow 3$.8-fold, spot 1 ; $14-3-3$ protein epsilon $\downarrow 2$.6-fold, spot 2; beta-soluble NSF attachment protein $\downarrow$ 1.6-fold, spot 3; guanine nucleotide-binding protein $\mathrm{G}(\mathrm{I}) / \mathrm{G}(\mathrm{S}) / \mathrm{G}(\mathrm{T})$ subunit beta-1 $\downarrow$ 4.4-fold, spot 4; 1-lactate dehydrogenase B chain $\downarrow 1$.9-fold, spot 5; creatine kinase $\downarrow 1$.5-fold, spot 6; tubulin alpha-1B chain $\downarrow 2$.1-fold, spot 7; heat shock cognate $71 \mathrm{kDa}$ protein $\downarrow 2$.1-fold, spot 8; dihydropyrimidinaserelated protein $2 \downarrow 1$.8-fold, spot 9; fructose-bisphosphate aldolase $C \downarrow 3$.0-fold, spot 10 and triosephosphate isomerase $\downarrow 2$.2-fold, spot 11. Upregulation was not detected (Figure 6b; Table 5b).

According to the current annotations (https://www.uniprot.org) in the UniProt database, the identified cerebellar proteins with changed expression level were involved in metabolism (4), signal transduction (3), brain development (3), cytoskeleton organization (2), aging (2), protein transport (1), protein folding (1), RNA processing (1), and apoptosis (1) (Figure 7d; Table 6b). 
Table 5. nLC-MS/MS analysis of significantly altered protein spots identified in the rat striatum (a) and cerebellum (b) isolated from animals after 6 months of morphine withdrawal.

\begin{tabular}{|c|c|c|c|c|c|c|c|c|c|c|}
\hline Spot & Accession & Gene & Protein Name & Mascot & Matched & $\mathrm{SC}^{\mathrm{a}}$ & $\mathbf{M W}^{\mathbf{b}}$ & $\mathrm{pI}^{\mathrm{c}}$ & Change & $p$ Value \\
\hline & Number & & & Score & Peptides & {$[\%]$} & (kDa) & & (Fold) & \\
\hline \multicolumn{11}{|c|}{ (a) STRIATUM Colloidal Coommassie Blue staining } \\
\hline 2 & P35704 & $\operatorname{Prd} x 2$ & Peroxiredoxin-2 & 388.2 & 7 & 31.3 & 21.8 & 5.2 & $\uparrow 1.8$ & 0.0214 \\
\hline 3 & P42123 & Ldhb & L-lactate dehydrogenase B chain & 1159.9 & 20 & 41.3 & 36.6 & 5.6 & $\downarrow 1.4$ & 0.0483 \\
\hline 4 & O88989 & Mdh1 & Malate dehydrogenase, cytoplasmic & 808.2 & 14 & 44.9 & 36.5 & 6.2 & $\downarrow 1.8$ & 0.0326 \\
\hline 5 & P60711 & Actb & Actin, cytoplasmic 1 & 1304.1 & 24 & 44.5 & 41.7 & 5.2 & $\uparrow 3.3$ & 0.0258 \\
\hline 6 & P63018 & Hspa8 & Heat shock cognate $71 \mathrm{kDa}$ protein & 1336.6 & 23 & 31.6 & 70.8 & 5.2 & $\uparrow 2.5$ & 0.0050 \\
\hline 7 & P02770 & Alb & Albumin & 651.8 & 12 & 18.3 & 68.7 & 6.1 & $\downarrow 2.4$ & 0.0115 \\
\hline 8 & P47942 & Dpysl2 & Dihydropyrimidinase-related protein 2 & 1104.7 & 17 & 35.5 & 62.2 & 5.9 & $\downarrow 1.7$ & 0.0352 \\
\hline 9 & P47942 & Dpysl2 & Dihydropyrimidinase-related protein 2 & 1997.6 & 31 & 56.3 & 62.2 & 5.9 & $\downarrow 2.0$ & 0.0244 \\
\hline 10 & P19804 & Nme2 & Nucleoside diphosphate kinase B & 575.2 & 11 & 59.2 & 17.3 & 7.8 & $\downarrow 2.0$ & 0.0458 \\
\hline \multicolumn{11}{|c|}{ (b) CEREBELLUM Colloidal Coommassie Blue staining } \\
\hline 1 & P61983 & Ywhag & 14-3-3 protein gamma & 1065.1 & 20 & 49.4 & 28.3 & 4.7 & $\downarrow 3.8$ & 0.0451 \\
\hline 2 & P62260 & Ywhae & 14-3-3 protein epsilon & 1373.3 & 23 & 49.8 & 29.2 & 4.5 & $\downarrow 2.7$ & 0.0214 \\
\hline 3 & P85969 & $\mathrm{Napb}$ & Beta-soluble NSF attachment protein & 418.7 & 9 & 26.6 & 33.4 & 5.2 & $\downarrow 1.6$ & 0.0172 \\
\hline 4 & P54311 & Gnb1 & $\begin{array}{l}\text { Guanine nucleotide-binding protein } \\
\mathrm{G}(\mathrm{I}) / \mathrm{G}(\mathrm{S}) / \mathrm{G}(\mathrm{T}) \text { subunit beta-1 }\end{array}$ & 497.7 & 9 & 22.9 & 37.4 & 5.6 & $\downarrow 4.4$ & 0.0035 \\
\hline 5 & P42123 & Ldhb & L-lactate dehydrogenase B chain & 1288.1 & 22 & 43.7 & 36.6 & 5.6 & $\downarrow 1.9$ & 0.0471 \\
\hline 6 & P07335 & $\mathrm{Ckb}$ & Creatine kinase B-type & 1531.4 & 22 & 53.8 & 42.7 & 5.3 & $\downarrow 1.5$ & 0.0246 \\
\hline 7 & Q6P9V9 & Tuba1b & Tubulin alpha-1B chain & 1209.4 & 21 & 53.7 & 50.1 & 4.8 & $\downarrow 2.1$ & 0.0041 \\
\hline 8 & P63018 & Hspa8 & Heat shock cognate $71 \mathrm{kDa}$ protein & 2437.8 & 37 & 45.5 & 70.8 & 5.2 & $\downarrow 2.1$ & 0.0072 \\
\hline
\end{tabular}


Table 5. Cont.

\begin{tabular}{|c|c|c|c|c|c|c|c|c|c|c|}
\hline Spot & Accession & Gene & Protein Name & Mascot & Matched & $\mathrm{SC}^{\mathrm{a}}$ & $\mathbf{M W}^{\mathbf{b}}$ & $\mathrm{pI}^{\mathrm{c}}$ & Change & $p$ Value \\
\hline & Number & & & Score & Peptides & {$[\%]$} & (kDa) & & (Fold) & \\
\hline 9 & P47942 & Dpysl2 & Dihydropyrimidinase-related protein 2 & 1684.2 & 25 & 48.8 & 62.2 & 5.9 & $\downarrow 1.8$ & 0.0174 \\
\hline 10 & P09117 & Aldoc & Fructose-bisphosphate aldolase $C$ & 1956.9 & 28 & 59 & 39.3 & 6.8 & $\downarrow 3.0$ & 0.0053 \\
\hline 11 & P48500 & Tpi1 & Triosephosphate isomerase & 859.3 & 12 & 50.6 & 26.8 & 7.7 & $\downarrow 2.2$ & 0.0200 \\
\hline
\end{tabular}

Table 6. Subcellular localization and function of altered proteins identified in the rat striatum (a) and cerebellum (b) isolated from animals after 6 months of morphine withdrawal; according to the current annotations (https:/ / www.uniprot.org) in the UniProt database.

\begin{tabular}{|c|c|c|c|c|c|}
\hline Spot & Accession & Protein Name & Change & Subcellular Localization & GO-Molecular Functions, Biological Processes \\
\hline & Number & & (Fold) & & \\
\hline \multicolumn{6}{|c|}{ (a) STRIATUM Colloidal Coommassie Blue staining } \\
\hline 1 & P0DP29 & Calmodulin-1 & $\downarrow 2.3$ & Cytoplasm, cytoskeleton & $\begin{array}{c}\text { Calcium-mediated signaling, activation } \\
\text { of adenylate cyclase activity, regulation } \\
\text { of cytokinesis }\end{array}$ \\
\hline 2 & P35704 & Peroxiredoxin-2 & $\uparrow 1.8$ & Cytoplasm & Antioxidant, response to oxidative stress \\
\hline 3 & P42123 & L-lactate dehydrogenase B chain & $\downarrow 1.4$ & Cytoplasm, mitochondrion & Pyruvate metabolic process \\
\hline 4 & O88989 & Malate dehydrogenase, cytoplasmic & $\downarrow 1.8$ & Cytoplasm & Krebs cycle \\
\hline 5 & P60711 & Actin, cytoplasmic 1 & $\uparrow 3.3$ & Cytoplasm, cytoskeleton, nucleus & Cell shape and movement \\
\hline 6 & P63018 & Heat shock cognate $71 \mathrm{kDa}$ protein & $\uparrow 2.5$ & Cell membrane, cytoplasm, nucleus & Protein folding, RNA processing, aging \\
\hline 7 & P02770 & Albumin & $\downarrow 2.4$ & Secreted & Transporter, apoptosis \\
\hline 8,9 & P47942 & Dihydropyrimidinase-related protein 2 & $\downarrow 1.7, \downarrow 2.0$ & $\begin{array}{l}\text { Cytoplasm, cytoskeleton, cell } \\
\text { membrane }\end{array}$ & $\begin{array}{c}\text { Brain development, neurogenesis, cell } \\
\text { movement }\end{array}$ \\
\hline 10 & P19804 & Nucleoside diphosphate kinase B & $\downarrow 2.0$ & Cytoplasm, nucleus & Nucleotide metabolism, transcription \\
\hline
\end{tabular}


Table 6. Cont.

\begin{tabular}{|c|c|c|c|c|c|}
\hline Spot & Accession & Protein Name & Change & Subcellular Localization & GO-Molecular Functions, Biological Processes \\
\hline & Number & & (Fold) & & \\
\hline \multicolumn{6}{|c|}{ (b) CEREBELLUM Colloidal Coommassie Blue staining } \\
\hline 1 & P61983 & 14-3-3 protein gamma & $\downarrow 3.8$ & Cytoplasm & Signal transducing adaptor protein \\
\hline 2 & P62260 & 14-3-3 protein epsilon & $\downarrow 2.6$ & Cytoplasm, nucleus & $\begin{array}{c}\text { Signal transducing adaptor protein, brain } \\
\text { development }\end{array}$ \\
\hline 3 & P85969 & Beta-soluble NSF attachment protein & $\downarrow 1.6$ & Cell membrane & ER-Golgi transport, protein transport \\
\hline 5 & P42123 & L-lactate dehydrogenase B chain & $\downarrow 1.9$ & $\begin{array}{l}\text { Cytoplasm, cell membrane, } \\
\text { mitochondrion }\end{array}$ & Pyruvate metabolic process \\
\hline 6 & P07335 & Creatine kinase B-type & $\downarrow 1.5$ & Cytoplasm & Brain development, creatine metabolism \\
\hline 7 & Q6P9V9 & Tubulin alpha-1B chain & $\downarrow 2.1$ & Cytoplasm, cytoskeleton & Cell shape and movement \\
\hline 8 & P63018 & Heat shock cognate $71 \mathrm{kDa}$ protein & $\downarrow 2.1$ & Cell membrane, cytoplasm, nucleus & Protein folding, RNA processing, aging \\
\hline 9 & P47942 & Dihydropyrimidinase-related protein 2 & $\downarrow 1.8$ & $\begin{array}{l}\text { Cytoplasm, cytoskeleton, cell } \\
\text { membrane }\end{array}$ & $\begin{array}{c}\text { Brain development, neurogenesis, cell } \\
\text { movement }\end{array}$ \\
\hline 10 & P09117 & Fructose-bisphosphate aldolase C & $\downarrow 3.0$ & Cytoplasm & Energy metabolism (glycolysis), aging, apoptosis \\
\hline 11 & P48500 & Triosephosphate isomerase & $\downarrow 2.2$ & Cytoplasm & Energy metabolism (glycolysis) \\
\hline
\end{tabular}




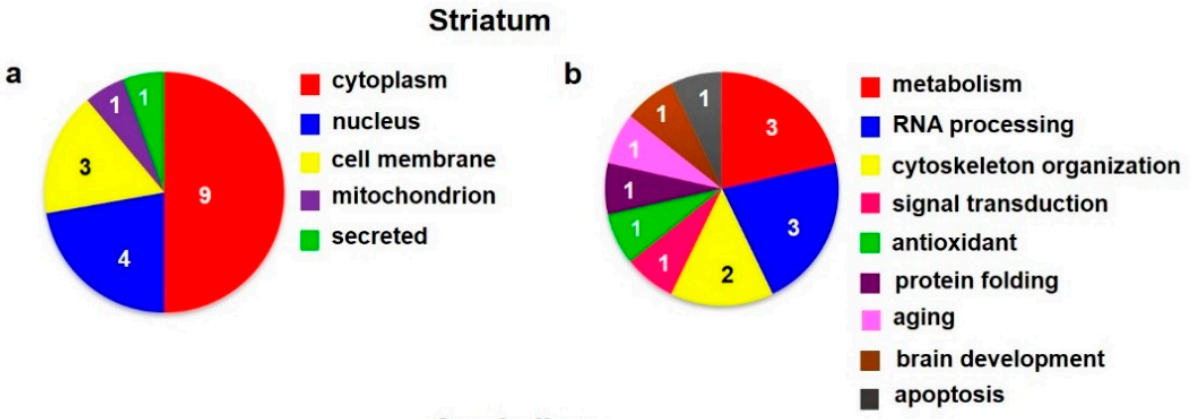

Cerebellum

C

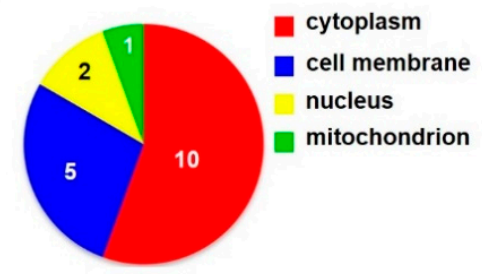

d

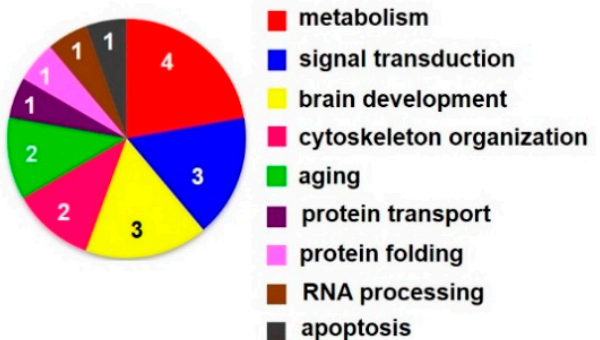

Figure 7. Subcellular localization $(\mathbf{a}, \mathbf{c})$ and function $(\mathbf{b}, \mathbf{d})$ of altered proteins identified in the rat striatum (upper panels) and cerebellum (lower panels) isolated from animals after 6 months of morphine withdrawal; according to the current annotations (https: / www.uniprot.org) in the UniProt database.

\section{Discussion}

During the last years, we applied 2D electrophoresis and label-free quantification to find the significant alterations in protein expression in the rat brain cortex and hippocampus after chronic morphine treatment $(10-50 \mathrm{mg} / \mathrm{kg}, 10$ days) followed by different withdrawal periods ( 3 weeks, 3 months, 6 months) $[15-17,28]$. The aim of this work was to analyze the spectrum of altered proteins in selected rat brain regions after 6-month morphine withdrawal. Our study could have two main limitations. First, some animals could be lost during morphine administration and withdrawal. For that reason, we had three extra animals in each testing group. Second, proteomic analyses require a large amount of tissue. For this purpose, we selected the stated brain regions (cortex, hippocampus, striatum, and cerebellum). This selection provided us with a relatively large amount of biological material.

2D-DIGE analysis of the rat hippocampus showed that 10-day morphine administration results in a significant change of six proteins functionally related to metabolism, cytoskeleton organization, neuronal plasticity, apoptosis, and oxidative stress. Interestingly, the number of differentially regulated proteins was increased to 13 after 3 weeks of drug abstinence. Moreover, the level of $\alpha$-synuclein (Snca), $\beta$-synuclein (Sncb), $\alpha$-enolase (Eno1), and glyceraldehyde-3-phosphate dehydrogenase (GAPDH) persisted altered for 3 weeks since the withdrawal of morphine [16]. Ten proteins were identified in hippocampal 2D CBB-stained gels 3 months after cessation of 10-day morphine treatment; 14 proteins were significantly hypophosphorylated [17]. Among these, several glycolytic enzymes, such as GAPDH, Eno1, phosphoglycerate mutase 1 (Pgam1), triosephosphate isomerase (Tpi1) and fructose-bisphosphate aldolase A (Aldoa) were decreased. In this work, the impact of 6-month morphine withdrawal on the change of total protein composition was higher-14 proteins were identified (Figure 1b; Table 1b). On the other hand, the number of dysregulated phosphoproteins was reduced from 14 to 6 (Figure 1a; Table 1a). The amount of glycolytic enzymes with significantly changed expression level was not so eminent. Pro- $\mathrm{Q}^{\circledR}$ Diamond staining revealed downregulation of Aldoa and an increased level of Tpi1 was detected by CBB protein staining. 
Previous studies of other authors have shown that enzymes involved in cellular metabolisms, such as glycolysis and Krebs cycle were altered in opioid-abusing patients and animal models [33,34]. Among the glycolytic enzymes, GAPDH is of particular interest. Its post-translational modifications may contribute to numerous cellular functions, including intracellular transport, cytoskeleton plasticity, heme chaperoning, transcription, and apoptosis $[18,35-40]$. However, its role in apoptosis is not clear. Some studies describe its proapoptotic function, others a protective role [41]. One of the typical features of GAPDH is its use as a loading marker in hundreds of studies. Notably, it was shown that the quantity of GAPDH can vary under stressful conditions [42].

Decreased level of superoxide dismutase [Cu-Zn] (Sod1) was detected in our hippocampal samples after 3 weeks of drug abstinence [16]. In this work, 6-month morphine withdrawal revealed downregulation of peroxiredoxin-2 $(\operatorname{Prd} x 2)$ and upregulation of Parkinson disease protein 7 homolog (Park7), see Table 1b. Park 7 is involved in the protection against oxidative stress [43]. Due to its protective role, Park 7 represents an ideal possible therapeutic target for Parkinson's disease (PD) and neurodegeneration [44]. We may hypothesize that stress-related pathways become activated during opioid withdrawal and can persist for several months after cessation of morphine administration.

Morphine could participate in the development of oxidative stress by promoting the formation of free radicals or reducing the activity of the antioxidant defense system which maintain redox homeostasis. Both these ways of action can be possibly combined [45]. Among the most important molecules playing a crucial role in cell protection against oxidative damage belong enzymes such as superoxide dismutase, glutathione peroxidase, catalase, and tripeptide glutathione [46]. The activity of antioxidant enzymes is closely associated with the production of reactive oxygen species (ROS) and reactive nitrogen species (RNS) that may lead to oxidative damage of DNA, lipids and proteins [47,48]. Results obtained by Motaghinejad et al. [49] showed that subcutaneous injection of morphine to rats significantly increased lipid peroxidation and decreased the activities of superoxide dismutase and glutathione peroxidase. Abdel-Zaher et al. [50] reported that glutamate levels and lipid peroxide malondialdehyde levels were significantly increased in the brain of morphine-treated mice. The impact of morphine on cellular redox balance may depend on multiple factors, such as species, age and sex of an organism, type of tissue, dosage, and length of usage [51].

The number of altered phosphorylated cytoskeletal proteins in the rat hippocampus was decreased from four (hypophosphorylation of F-actin-capping subunit beta (Capzb); actin, cytoplasmic 2 (Actg1); glial fibrillary acidic protein (GFAP) and tubulin alpha-1A chain (Tuba1a)) to one hyperphosphorylated tubulin alpha-1B chain (Tuba1b) when compared the period of abstinence 3 and 6 months. The change in protein expression was almost similar after 3 or 6 months of drug withdrawal and resulted in a decreased level of tubulin beta-4B chain (Tubb4b), tubulin polymerization promoting protein (Tppp), actin, cytoplasmic 1 (Actb), tubulin beta chain (Tubb4b), and alpha-internexin (Ina). These findings suggest that protracted morphine abstinence may cause long-term homeostatic changes in hippocampal plasticity [52]. However, according to our unpublished behavioral studies, we did not find significant differences between morphine-withdrawn and control animals. We may speculate that proteomic changes in the rat hippocampus after 6 months of morphine withdrawal do not require alterations in a certain behavior or functional state.

Twenty-eight significantly altered proteins were detected in the rat brain cortex after treatment with morphine for 10 days, this amount was reduced to 14 proteins after 3 weeks of abstinence [15], to 10 proteins after 3-month morphine withdrawal [17] and to only three proteins after 6-month drug abstinence. Chronic morphine treatment resulted in the decreased level of several glycolytic enzymes, such as Tpi1, Pgam1, GAPDH, Aldoa, pyruvate kinase PKM $(P k m)$, and phosphoglycerate kinase 1 (Pgk1). The expression level of $P k m, P g k 1$ and GAPDH persisted decreased for 3 months of drug withdrawal and was not altered after 6 months of abstinence. It would be useful to confirm whether proteomicsindicated alterations in enzyme levels reflect changes in their activity. The change in protein 
expression does not necessarily mean the change in functional activity, as described by Bodzon-Kulakowska et al. [53] and Antolak et al. [26]. We assume that simultaneous alterations in both features may represent new insight into brain energy homeostasis.

Increasing evidence suggests that the striatum and cerebellum participate in drug addiction [54-58]. As a complement to proteomic analyses of rat hippocampus and cortex, we also performed the screening of protein alterations in the rat striatum and cerebellum after 6-month morphine withdrawal. Interestingly, the number of altered proteins was increased in both the striatum and cerebellum after 6-month drug withdrawal in comparison with the effect of 3-month morphine abstinence. In the striatum, the number of differentially expressed proteins was increased from 7 to 10 while in the cerebellum from 4 to 11 . The majority of changes were related to metabolic alterations (L-lactate dehydrogenase $B$ chain $(L d h b)$, malate dehydrogenase $(L d h 1)$, creatine kinase B-type $(C k b)$, fructose-bisphosphate aldolase C (Aldoc), and Tpi1) (Figure 6; Table 6a,b). Taken together, our results suggest that protracted morphine withdrawal causes significant proteomic changes in the energy metabolism of different rat brain parts. We assume that deeper metabolic investigation into the brain structures may reveal numerous differences in glucose metabolism, the tricarboxylic acid cycle (TCA) and fatty acid metabolism. In addition, we may expect changes in metabolites related to antioxidant and nucleotide pathways. However, detailed studies are missing.

\section{Conclusions}

Our data show that the rat hippocampus is more affected than the forebrain cortex in both protein phosphorylation and protein expression by 6-month morphine withdrawal. Gene Ontology (GO) enrichment analysis for 20 up- and downregulated proteins in the hippocampus revealed that the most enriched $\mathrm{GO}$ terms were associated with alterations in energy metabolism, cytoskeleton organization, and oxidative stress response. Our previous proteomic studies indicated that 10-day morphine administration results in significant alterations related to energy metabolism. Moreover, these changes persisted several weeks/months after the cessation of 10-day morphine treatment. We hypothesize that alterations in energy metabolism may be one of the functional consequences of the impaired antioxidant defense system. However, these questions need further investigation.

Author Contributions: Conceptualization, H.U. and J.N.; Methodology, H.U., A.E. and L.H.; Investigation, H.U.; Data Analysis and Interpretation, H.U.; Visualization, H.U.; Project Administration and Supervision, P.S. and J.N.; Writing-Original Draft, H.U. and P.S. All authors have read and agreed to the published version of the manuscript.

Funding: This work was supported by the Czech Science Foundation (grant number 19-03295S) and by the Institute of Physiology (RVO:67985823). This work used instruments provided by C4Sys infrastructure.

Institutional Review Board Statement: The study was approved by the Animal Ethics Committee of the Faculty of Science, Charles University (Prague, Czech Republic), and by the Ministry of Education, Youth and Sports of the Czech Republic (license number MSMT-1479/2019-6).

Data Availability Statement: Data are contained within the article.

Conflicts of Interest: The authors declare no conflict of interest.

\section{References}

1. Azevedo Neto, J.; Constanzini, A.; De Giorgio, R.; Lambert, D.G.; Ruzza, C.; Calò, G. Biased versus partial agonism in the search for safer opioid analgesics. Molecules 2020, 25, 3870. [CrossRef]

2. Paul, A.K.; Gueven, N.; Dietis, N. Profiling the effects of repetitive morphine administration on motor behavior in rats. Molecules 2021, 26, 4355. [CrossRef]

3. Chen, Y.; Mestek, A.; Liu, J.; Hurley, J.A.; Yu, L. Molecular cloning and functional expression of a mu-opioid receptor from rat brain. Mol. Pharmacol. 1993, 44, 8-12. [CrossRef]

4. Pacifici, G.M. Metabolism and pharmacokinetics of morphine in neonates: A review. Clinics 2016, 71, 474-480. [CrossRef] 
5. Bourova, L.; Vosahlikova, M.; Kagan, D.; Dlouha, K.; Novotny, J.; Svoboda, P. Long-term adaptation to high doses of morphine causes desensitization of $\mu$-OR- and $\delta$-OR-stimulated G-protein response in forebrain cortex but does not decrease the amount of G-protein alpha subunit. Med. Sci. Monit. 2010, 16, 260-270.

6. Sim, L.J.; Selley, D.E.; Dworkin, S.I.; Childers, S.R. Effects of chronic morphine administration on mu opioid receptor-stimulated [35S] GTPgammaS autoradiography in rat brain. J. Neurosci. 1996, 16, 2684-2692. [CrossRef]

7. Selley, D.E.; Liu, Q.; Childers, S.R. Signal transduction correlates of $\mu$ opioid agonist intrinsic efficacy: Receptor-stimulated [35S] GTP $\gamma S$ binding in mMOR-CHO cells and rat thalamus. J. Pharm. Exp. Ther. 1998, 285, 496-505.

8. Selley, D.E.; Cao, Q.L.; Liu, Q.; Childers, S.R. Effect of sodium on agonist efficacy for G-protein activation in $\mu$-opioid receptortransfected CHO cells and rat thalamus. Br. J. Pharmacol. 2000, 130, 987-996. [CrossRef]

9. Sim-Selley, L.J.; Selley, D.E.; Vogt, L.J.; Childers, S.R.; Martin, T.J. Chronic heroin self-administration desensitizes mu opioid receptor-activated G-proteins in specific regions of rat brain. J. Neurosci. 2000, 20, 4555-4562. [CrossRef] [PubMed]

10. Maher, C.E.; Selley, D.E.; Childers, S.R. Relationship of mu opioid receptor binding to activation of G-proteins in specific rat brain regions. Biochem. Pharmacol. 2000, 59, 1395-1401. [CrossRef]

11. Maher, C.E.; Martin, T.J.; Childers, S.R. Mechanisms of mu opioid receptor/G-protein desensitization in brain by chronic heroin administration. Life Sci. 2005, 77, 1140-1154. [CrossRef] [PubMed]

12. Ujcikova, H.; Dlouha, K.; Roubalova, L.; Vosahlikova, M.; Kagan, D.; Svoboda, P. Up-regulation of adenylylcyclases I and II induced by long-term adaptation of rats to morphine fades away 20 days after morphine withdrawal. Biochim. Et Biophys. Acta 2011, 1810, 1220-1229. [CrossRef] [PubMed]

13. Ujcikova, H.; Brejchova, J.; Vosahlikova, M.; Kagan, D.; Dlouha, K.; Sykora, J.; Merta, L.; Drastichova, Z.; Novotny, J.; Ostasov, P.; et al. Opioid-receptor (OR) signaling cascades in rat cerebral cortex and model cell lines: The role of plasma membrane structure. Physiol. Res. 2014, 63, S165-S176. [CrossRef] [PubMed]

14. Ujcikova, H.; Eckhardt, A.; Kagan, D.; Roubalova, L.; Svoboda, P. Proteomic analysis of post-nuclear supernatant and percollpurified membranes prepared from brain cortex of rats exposed to increasing doses of morphine. Proteome Sci. 2014, 12, 11. [CrossRef] [PubMed]

15. Ujcikova, H.; Vosahlikova, M.; Roubalova, L.; Svoboda, P. Proteomic analysis of protein composition of rat forebrain cortex exposed to morphine for 10 days; comparison with animals exposed to morphine and subsequently nurtured for 20 days in the absence of this drug. J. Proteom. 2016, 145, 11-23. [CrossRef] [PubMed]

16. Ujcikova, H.; Cechova, K.; Jagr, M.; Roubalova, L.; Vosahlikova, M.; Svoboda, P. Proteomic analysis of protein composition of rat hippocampus exposed to morphine for 10 days; comparison with animals after 20 days of morphine withdrawal. PLoS ONE 2020, 15, e0231721. [CrossRef] [PubMed]

17. Ujcikova, H.; Hejnova, L.; Eckhardt, A.; Roubalova, L.; Novotny, J.; Svoboda, P. Impact of three-month morphine withdrawal on rat brain cortex, hippocampus, striatum and cerebellum: Proteomic and phosphoproteomic studies. Neurochem. Int. 2021, 144, 104975. [CrossRef] [PubMed]

18. Kim, S.Y.; Chudapongse, N.; Lee, S.M.; Levin, M.C.; Oh, J.T.; Park, H.J.; Ho, I.K. Proteomic analysis of phosphotyrosyl proteins in morphine-dependent rat brains. Mol. Brain Res. 2005, 133, 58-70. [CrossRef]

19. Bierczynska-Krzysik, A.; Bonar, E.; Drabik, A.; Noga, M.; Suder, P.; Dylag, T.; Dubin, A.; Kotlinska, J.; Silberring, J. Rat brain proteome in morphine dependence. Neurochem. Int. 2006, 49, 401-406. [CrossRef] [PubMed]

20. Bierczynska-Krzysik, A.; Pradeep, J.J.P.; Silberring, J.; Kotlinska, J.; Dylag, T.; Cabatic, M.; Lubec, G. Proteomic analysis of rat cerebral cortex, hippocampus and striatum after exposure to morphine. Int. J. Mol. Med. 2006, 18, 775-784. [CrossRef]

21. Li, K.W.; Jimenez, C.R.; van der Schors, R.C.; Hornshaw, M.P.; Schoffelmeer, A.N.M.; Smit, A.B. Intermittent administration of morphine alters protein expression in rat nucleus accumbens. Proteomics 2006, 6, 2003-2008. [CrossRef] [PubMed]

22. Chen, X.L.; Lu, G.; Gong, Y.X.; Zhao, L.C.; Chen, J.; Chi, Z.Q.; Yang, Y.M.; Chen, Z.; Li, Q.L.; Liu, J.G. Expression changes of hippocampal energy metabolism enzymes contribute to behavioral abnormalities during chronic morphine treatment. Cell Res. 2007, 17, 689-700. [CrossRef] [PubMed]

23. Jiang, X.; Li, J.; Ma, L. Metabolic enzymes link morphine withdrawal with metabolic disorder. Cell Res. 2007, 17, 741-743. [CrossRef]

24. Bodzon-Kułakowska, A.; Suder, P.; Mak, P.; Bierczynska-Krzysik, A.; Lubec, G.; Walczak, B.; Kotlinska, J.; Lubec, G. Proteomic analysis of striatal neuronal cell cultures after morphine administration. J. Sep. Sci. 2009, 32, 1200-1210. [CrossRef] [PubMed]

25. Bodzon-Kułakowska, A.; Kułakowski, K.; Drabik, A.; Moszczynski, A.; Silberring, J.; Suder, P. Morphinome-A meta-analysis applied to proteomics. Proteomics 2011, 11, 5-21. [CrossRef]

26. Antolak, A.; Bodzon-Kułakowska, A.; Cetnarska, E.; Pietruszka, M.; Marszałek-Grabska, M.; Kotlińska, J.; Suder, P. Proteomic data in morphine addiction versus real protein activity: Metabolic enzymes. J. Cell. Biochem. 2017, 118, 4323-4330. [CrossRef]

27. Bodzon-Kułakowska, A.; Padrtova, T.; Drabik, A.; Ner-Kluza, J.; Antolak, A.; Kułakowski, K.; Suder, P. Morphinome databaseThe database of proteins altered by morphine administration-An update. J. Proteom. 2019, 190, 21-26. [CrossRef] [PubMed]

28. Drastichova, Z.; Hejnova, L.; Moravcova, R.; Novotny, J. Proteomic analysis unveils expressional changes in cytoskeleton- and synaptic plasticity-associated proteins in rat brain six months after withdrawal from morphine. Life 2021, 11, 683. [CrossRef] [PubMed]

29. Marcus, K.; Lelong, C.; Rabilloud, T. What room for two-dimensional gel-based proteomics in a shotgun proteomics world? Proteomes 2020, 8, 17. [CrossRef] [PubMed] 
30. Schulenberg, B.; Goodman, T.N.; Aggeler, R.; Capaldi, R.A.; Patton, W.F. Characterization of dynamic and steady-state protein phosphorylation using fluorescent phosphoprotein gel stain and mass spectrometry. Electrophoresis 2004, 25, 2526-2532. [CrossRef] [PubMed]

31. Eckhardt, A.; Jagr, M.; Pataridis, S.; Miksik, I. Proteomic analysis of human tooth pulp: Proteomics of human tooth. J. Endod. 2014, 40, 1961-1966. [CrossRef] [PubMed]

32. Jágr, M.; Eckhardt, A.; Pataridis, S.; Foltan, R.; Mysak, J.; Miksik, I. Proteomic analysis of human tooth pulp proteomesComparison of caries-resistant and caries-susceptible persons. J. Proteom. 2016, 145, 127-136. [CrossRef] [PubMed]

33. Dodge, P.W.; Takemori, A.E. Effects of morphine, nalnorphine and pentobarbital alone and combination on cerebral glycolytic substrates and cofactors of rats in vivo. Biochem. Pharmacol. 1972, 21, 287-294. [CrossRef]

34. Sherman, A.D.; Mitchell, C.L. Effects of morphine and pain on brain intermediary metabolism. Neuropharmacology 1972, 11, 871-877. [CrossRef]

35. Chuang, D.M.; Hough, C.; Senatorov, V.V. Glyceraldehyde-3-phosphate dehydrogenase, apoptosis, and neurodegenerative diseases. Annu. Rev. Pharmacol. Toxicol. 2005, 45, 269-290. [CrossRef] [PubMed]

36. Tristan, C.; Shahani, N.; Sedlak, T.W.; Sawa, A. The diverse functions of GAPDH: Views from different subcellular compartments. Cell. Signal. 2011, 23, 317-323. [CrossRef] [PubMed]

37. Landino, L.M.; Hagedorn, T.D.; Kennett, K.L. Evidence for thiol/disulfide exchange reactions between tubulin and glyceraldehyde-3-phosphate dehydrogenase. Cytoskeleton 2014, 71, 707-718. [CrossRef] [PubMed]

38. Kunjithapatham, R.; Geschwind, J.F.; Devine, L.; Boronina, T.N.; O’Meally, R.N.; Cole, R.N.; Torbenson, R.S.; GanapathyKanniappan, S. Occurence of a multimer high-molecular-weight glyceraldehyde-3-phosphate dehydrogenase in human serum. J. Proteome Res. 2015, 14, 1645-1656. [CrossRef] [PubMed]

39. Tisdale, E.J.; Talati, N.K.; Artalejo, C.R.; Shisheva, A. GAPDH binds Akt to facilitate cargo transport in the early secretory pathway. Exp. Cell Res. 2016, 349, 310-319. [CrossRef]

40. Lazarev, V.F.; Guzhova, I.V.; Margulis, B.A. Glyceraldehyde-3-phosphate dehydrogenase is a multifaceted therapeutic target. Pharmaceutics 2020, 12, 416. [CrossRef] [PubMed]

41. Collel, A.; Green, D.R.; Ricci, J.E. Novel roles for GAPDH in cell death and carcinogenesis. Cell Death Differ. 2009, 16, 1573-1581. [CrossRef] [PubMed]

42. Goasdoue, K.; Awabdy, D.; Bjorkman, S.T.; Miller, S. Standard loading controls are not reliable for Western blot quantification across brain development or in pathological conditions. Electrophoresis 2016, 37, 630-634. [CrossRef]

43. Repici, M.; Giorgini, M. DJ-1 in Parkinson's disease: Clinical insights and therapeutic perspectives. J. Clin. Med. 2019, 8, 1377. [CrossRef] [PubMed]

44. Dos Santos, M.C.T.; Scheller, D.; Schulte, C.; Mesa, I.R.; Colman, P.; Bujac, S.R.; Bell, R.; Berteau, C.; Perez, L.T.; Lachmann, I.; et al Evaluation of cerebrospinal fluid proteins as potential biomarkers for early stage Parkinson's disease diagnosis. PLoS ONE 2018, 13, e206536. [CrossRef] [PubMed]

45. Zeng, X.S.; Geng, W.S.; Wang, Z.Q.; Jia, J.J. Morphine addiction and oxidative stress: The potential effects of thioredoxin-1. Front Pharmacol. 2020, 11, 82. [CrossRef]

46. Kurutas, E.B. The importance of antioxidants which play the role in cellular response against oxidative/nitrosative stress: Current state. Nutr. J. 2016, 15, 71. [CrossRef]

47. Zhang, Y.T.; Zheng, Q.S.; Pan, J.; Zheng, R.L. Oxidative damage of biomolecules in mouse liver induced by morphine and protected by antioxidants. Basic Clin. Pharmacol. Toxicol. 2004, 95, 53-58. [CrossRef] [PubMed]

48. Ozmen, I.; Naziroglu, M.; Alici, H.A.; Sahin, F.; Cengiz, M.; Eren, I. Spinal morphine administration reduces the fatty acid contents in spinal cord and brain by increasing oxidative stress. Neurochem. Res. 2007, 32, 19-25. [CrossRef] [PubMed]

49. Motaghinejad, M.; Karimian, M.; Motaghinejad, O.; Shabab, B.; Yazdani, I.; Fatima, S. Protective effects of various dosage of curcumin against morphine induced apoptosis and oxidative stress in rat isolated hippocampus. Pharmacol. Rep. 2015, 67, 230-235. [CrossRef] [PubMed]

50. Abdel-Zaher, A.O.; Mostafa, M.G.; Farghly, H.M.; Hamdy, M.M.; Omran, G.A.; Al-Shaibani, N.K.M. Inhibition of brain oxidative stress and inducible nitric oxide synthase expression by thymoquinone attenuates the development of morphine tolerance and dependence in mice. Eur. J. Pharmacol. 2013, 702, 62-70. [CrossRef] [PubMed]

51. Skrabalova, J.; Drastichova, Z.; Novotny, J. Morphine as a potential oxidative stress-causing agent. Mini Rev. Org. Chem. 2013, 10, 367-372. [CrossRef]

52. Mattei, V.; Martellucci, S.; Santilli, F.; Manganelli, V.; Garofalo, T.; Candelise, N.; Caruso, A.; Sorice, M.; Scaccianoce, S.; Misasi, R. Morphine withdrawal modifies prion protein expression in rat hippocampus. PLoS ONE 2017, 12, e0169571.

53. Bodzon-Kulakowska, A.; Suder, P.; Drabik, A.; Kotlinska, J.H.; Silberring, J. Constant activity of glutamine synthetase after morphine administration versus proteomic results. Anal. Bioanal. Chem. 2010, 398, 2939-2942. [CrossRef]

54. Everitt, B.J.; Robbins, T.W. From the ventral to the dorsal striatum: Devolving views of their roles in drug addiction. Neurosci. Biobehav. Rev. 2013, 37, 1946-1954. [CrossRef]

55. Yager, L.M.; Garcia, A.F.; Wunsch, A.M.; Ferguson, S.M. The ins and outs of the striatum: Role in drug addiction. Neuroscience 2015, 301, 529-541. [CrossRef] 
56. Shen, S.; Jiang, X.; Li, J.; Straubinger, R.M.; Suarez, M.; Tu, C.; Duan, X.; Thompson, A.C.; Qu, J. Large-scale, ion-current-based proteomic investigation of the rat striatal proteome in a model of short- and long-term cocaine withdrawal. J. Proteome Res. 2016, 15, 1702-1716. [CrossRef]

57. Miquel, M.; Vazquez-Sanroman, D.; Carbo-Gas, M.; Gil-Miravet, I.; Sanchis-Sequra, C.; Carulli, D.; Manzo, J.; Coria-Avila, G.A. Have we been ignoring the elephant in the room? Seven arguments for considering the cerebellum as part of addiction circuitry. Neurosci. Biobehav. Rev. 2016, 60, 1-11. [CrossRef]

58. Ranjbar, H.; Soti, M.; Banazadeh, M.; Saleki, K.; Kohlmeier, K.A.; Shabani, M. Addiction and the cerebellum with a focus on actions of opioid receptors. Neurosci. Biobehav. Rev. 2021, 131, 229-247. [CrossRef] 